B I B L I O G R A F Í A

1. Toyoda Y, Shinohara N, Harabayashi T. Survival and prognostic classification of patients with metastatic renal cell carcinoma of bone. Eur Urol. 2007;52:163-9.

2. Sheth S, Scatarige JC, Horton KM. Current concepts in the diagnosis and management of renal cell carcinoma: role of multidetector CT and three-dimensional CT. Radiographics. 2001;21:237-41.

3. Zisman A, Pantuck AJ, Dorey F. Improved prognostication of renal cell carcinoma using integrated staging system. J Clin Oncol. 2001;19:1649-55.

4. Whelan P. The medical treatment of metastatic renal cell carcinoma. EUA Update Series. 2003;1:237-44.

5. Shinojima T, Nakajima Y, Kiguchi H. Renal cell carcinoma metastatic to the ovary: a case report. Nippon Hinyokika Gak Zass. 2001;92:694-7.
M. Álvarez-Múgica ${ }^{\mathrm{a}, *}$, V. Bulnes Vázquez ${ }^{\mathrm{b}}$, A. Jalón Monzón ${ }^{\mathrm{c}}$ y F.J. Regadera Sejas ${ }^{c}$

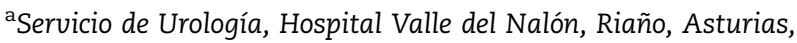
España

bervicio de Radiodiagnóstico, Hospital Álvarez-Buylla, Mieres, Asturias, España

'Servicio de Urología, Hospital Universitario Central de Asturias, Oviedo, España

*Autor para correspondencia.

Correo electrónico: malvarezmug@gmail.com

(M. Álvarez-Múgica).

\title{
Tumor filoide de la vesícula seminal: caso clínico y revisión de la literatura
}

\section{Phyllodes tumour of the seminal vesicle: case report and revision of literature}

\section{Sr. Director:}

Le presentamos el caso de un hombre con 64 años, asintomático, con masa supraprostática diagnosticada en ultrasonido transrectal. El nivel sérico del antígeno específico de la próstata (PSA) fue $0,53 \mu \mathrm{g} / \mathrm{l}$. La resonancia magnética (RMN) pélvica mostró una formación de bordes regulares, de predominio quístico, con una vegetación interna sólida, en la topografía de la vesícula seminal izquierda, no presentando ninguna señal de agresividad local o regional (fig. 1).
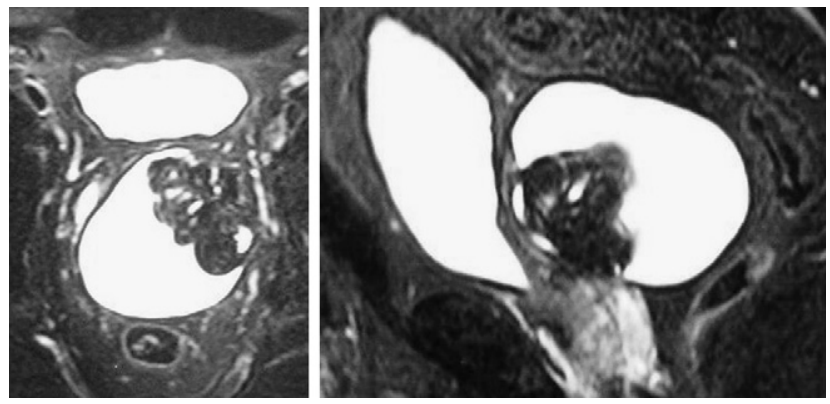

Figura 1 - RMN axial y sagital: formación en la topografía de la vesícula seminal izquierda, de bordes regulares, de predominio quístico, con una vegetación sólida de $5 \mathrm{~cm}$ en su interior.
Por laparotomía media infraumbilical y por corte de la bolsa de Douglas, se hizo la exéresis completa de la masa (fig. 2), adherente a la próstata, no siendo posible identificar la vesícula seminal izquierda. El periodo posquirúrgico transcurrió sin problemas.

El examen patológico mostró una formación quística con un nódulo sólido papilar. Al corte era compacta y elástica, observándose tejido prostático y de la vesícula seminal en su

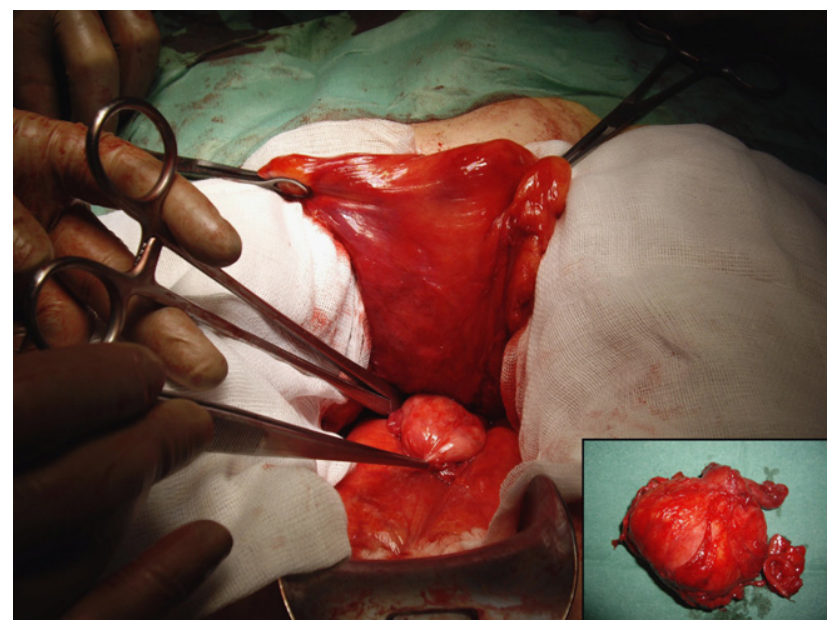

Figura 2 - Cirugía: exposición del tumor con la vejiga desplazada hacía delante (imagen pequeña-pieza quirúrgica). 
periferia. En microscopia, el tumor tenía áreas estromales y glandulares con arquitectura en hoja, diagnosticando tumor filoide. No presentaba ningún factor de agresividad, por lo que fue considerado de bajo grado. La imunohistoquímica fue negativa para el antígeno específico de la próstata y fosfatase ácida prostática, reforzando el origen en la vesícula seminal.

Un año después de la cirugía, el paciente se encuentra bien, asintomático y sin señal de tumor residual o recidiva en los estudios de imagen.

Los tumores filoides son neoplasias con un componente epitelial y otro estromal ${ }^{1}$, que surgen frecuentemente en el seno. Raramente se desarrollan en la próstata, siendo que hay unos 15 casos publicados con origen en las vesículas seminales. Se presentan frecuentemente con síntomas del tracto urinario bajo, hematuria, hematospermia o masa al examen rectal ${ }^{1-3}$. Poseen características típicas pero no únicas en los estudios de imagen ${ }^{4}$.

El tratamiento adecuado es la exéresis quirúrgica del tumor. Estudios indican que, incluso en los menos agresivos, la recidiva local es la regla ${ }^{1}$, con algunos casos en que surgieron sarcoma ${ }^{1,5}$, invasión local y metástasis pulmonares ${ }^{1,2,6,7}$, principalmente en los de alto grado (con hipercelularidad, atipias nucleares, actividad mitótica ó aumento de la razón estroma/epitélio) ${ }^{1}$, incluso después de una cirugía radical. Como no hay metástasis linfáticas descritas, no hay indicación para linfadenectomia ${ }^{8}$.

El papel de la radioterapia y quimioterapia ${ }^{2,4,7}$ sigue por establecer, a pesar de un caso de remisión de metástasis pulmonares ${ }^{7}$.
B I B L I O G R A F Í A

1. Bostwick D, Hossain D. Phyllodes tumor of the prostate: longterm follow-up study of 23 cases. J Urol. 2004;172:894-9.

2. Fain J, Cosnow I, King B, Bostwick D. Cystosarcoma phyllodes of the seminal vesicle. Cancer. 1993;71:2055-61.

3. Schapmans S, van Leuven L, Cortvriend J, Beelaerts W, van Erps P. Phyllodes tumor of the prostate. Eur Urol. 2000;38: 649-53.

4. Olson E, Trambert M, Mattrey R. Cystosarcoma phyllodes of the prostate: MRI Findings. Abdom Imaging. 1994;19:180-1.

5. Herawi M, Epstein J. Specialized stromal tumors of the prostate: a clinicopathologic study of 50 cases. Am J Surg Pathol. 2006;30:304-694.

6. Abe $H$, Nishimura $T$, Miura $T$, Uchikoba $T$. Cystosarcoma phyllodes of the seminal vesicle. Int J Urol. 2002;9:599-601.

7. Lam $\mathrm{K}$, Yeo W. Chemotherapy induced complete remission in malignant phyllodes tumor of the prostate metastasizing to the lung. J Urol. 2002;168:1104-5.

8. Jackson D, Clements R. Sonographic and radiological features of cystosarcoma phyllodes of the Prostate. Clinical Radiology. 1999;54:473-85.

R.O. Soares*, T.P. Correia, A. Cardoso y M. Cerqueira

Servicio de Urología, Hospital Pedro Hispano, Matosinhos, Portugal

Autor para correspondencia.

Correo electrónico: ricardosoares81@gmail.com (R.O. Soares).

\section{Pseudoaneurisma de arteria renal tras nefrectomía parcial laparoscópica. Diagnóstico, tratamiento y revisión bibliográfica}

\section{Renal artery pseudoaneurysm after partial nephrectomy. Diagnosis, treatment and literature review}

\section{Sr. Director:}

Desde mayo de 2006 hasta diciembre de 2008 se han realizado 9 nefrectomías parciales laparoscópicas (NPL) en nuestro servicio. Presentamos el caso de un varón de 61 años diagnosticado de forma incidental de un tumor renal derecho de $2,5 \mathrm{~cm}$, en polo inferior.

Se practicó NPL con un tiempo quirúrgico de $220 \mathrm{~min}$, un tiempo de isquemia de $32 \mathrm{~min}$ y un sangrado de $200 \mathrm{ml}$. La resección se realizó con corte frío y un margen de seguridad de $1 \mathrm{~cm}$. Posteriormente, se suturó la vía urinaria y el lecho quirúrgico con poliglactina $3-0$, sobre dicho lecho de resección se añadió Floseal $^{\circledR}$ y se colocó una membrana de Surgicel ${ }^{\circledR}$. La sutura del parénquima se realizó mediante poliglactina del 1 y Hemo-locks ${ }^{\circledR}$ para mantener tensión.
El resultado anatomopatológico fue carcinoma de células claras con áreas de crecimiento papilar, grado II de Furhman. El tamaño tumoral fue de $2,7 \mathrm{~cm}$, con márgenes quirúrgicos, cápsula y grasa perirrenal libres de infiltración.

Finalizada la cirugía presentó hematuria leve, que $24 \mathrm{~h}$ después coincidiendo con el inicio de la deambulación se agravó requiriendo lavado continuo y transfusión de 2 concentrados de hematíes. El paciente fue dado de alta sin sonda a los 4 días de la intervención.

Cuatro días después del alta, el paciente presentó episodio de hematuria y pérdida de conciencia. Se realizó una TC (fig. 1), observando en el riñón derecho una imagen sacular de $2,5 \mathrm{~cm}$ que capta contraste en fase arterial y no en fase excretora; sospechando la existencia de un pseudoaneurisma de arteria renal (PAR). 